\title{
Characterization of Titanium Dioxide by Microwave Assisted
}

\section{Homogeneous Precipitation}

\author{
Di Liu, Shi-ting Deng, Hong Yu, Yong-guang $\mathrm{Bi}^{*}$ \\ College of Pharmacy, Guangdong Pharmaceutical University, Guangzhou, Guangdong, China \\ ${ }^{*}$ Corresponding author:biyongguang2002@163.com
}

Keywords: $\mathrm{TiO}_{2}$ microsphere; Self-assembled; Homogeneous precipitation; Microwave irradiation. Abstract. Nanoparticulate $\mathrm{TiO}_{2}$ microspheres were synthesized by microwave assisted homogeneous precipitation. The effect of concentration of oxysulfate sulfuric acid complex hydrate $\left(\mathrm{TiOSO}_{4} \cdot \mathrm{xH}_{2} \mathrm{SO}_{4} \cdot \mathrm{xH}_{2} \mathrm{O}\right.$ ), urea and temperature were investigated. The obtained powder was characterized by X-ray diffraction (XRD), Scanning Electron Microscopy (SEM). The results showed that obtained $\mathrm{TiO}_{2}$ were pure-phase anatase with diameters of about $2 \mu \mathrm{m}$ with $5.4383 \mathrm{~g}$ $\mathrm{TiOSO}_{4} \cdot \mathrm{xH}_{2} \mathrm{SO}_{4} \cdot \mathrm{xH}_{2} \mathrm{O}, 12.24 \mathrm{~g}$ urea and 2\% Span20 and 5\% PEG600 in 20mL deionized water.

\section{Introduction}

Titanium dioxide $\left(\mathrm{TiO}_{2}\right)$ presents in three main phases, namely anatase, rutile and brookite. It is well known that rutile is the stable phase because of different distortion degree and connection mode (two edges are shared in rutile, four edges in anatase) while anatase shows higher photocatalytic activity due to the lower recombination rate of photogenerated electron-hole pair than rutile and has high adsorption capacity towards organic contaminates [1]. Numerous efforts have been devoted to synthesize $\mathrm{TiO}_{2}$ with different morphology including sol-gel process, hydrothermal treatment, micro-emulsion and anodization method [2]. Nevertheless, these methods described above require expensive precursors and strict equipment condition and greatly limit the application of $\mathrm{TiO}_{2}$. Homegeneous precipitation method, has been widely applied to synthesize variety of metallic oxide such as $\mathrm{TiO}_{2}, \mathrm{Al}_{2} \mathrm{O}_{3}, \mathrm{ZnO}$ because of its simple operation, cheap precursors and ease for mass production [3], urea is demonstrated as a precipitation agent in this method which can slowly release ammonia to ensure the nucleation rate is greater than growth rate during precipitation and obtain better crystallinity, regular shape and size of particles.

Besides, microwave irradiation had drawn much attention since the first report of microwave-assisted synthesis in 1986 [4] due to its volumetric heating, simultaneous heating and rapid heating rate, different from the conventional annealing process which temperature rise through convection, conduction and irradiation. To the best of our knowledge, the method combined homogenous precipitation with microwave irradiation has not been investigated to prepare anatase.

In the present work, anatase was synthesized through homogenous precipitation assisted by microwave irradiation, taking titanium oxysulfate sulfuric acid complex hydrate $\left(\mathrm{TiOSO}_{4} \cdot \mathrm{xH}_{2} \mathrm{SO}_{4} \cdot \mathrm{xH}_{2} \mathrm{O}\right)$ as $\mathrm{Ti}$ source and urea as precipitation agent with $2 \%$ Span 20 and $5 \%$ PEG600 as surfactant. The effect of concentration of $\mathrm{TiOSO}_{4} \cdot \mathrm{xH}_{2} \mathrm{SO}_{4} \cdot \mathrm{xH}_{2} \mathrm{O}$ and urea, temperature were all investigated.

\section{Materials and Methods}

Chemicals. Titanium oxysulfate sulfuric acid complex hydrate $\left(\mathrm{TiOSO}_{4} \cdot \mathrm{xH}_{2} \mathrm{SO}_{4} \cdot \mathrm{xH}_{2} \mathrm{O}\right)$ was 
purchased from Aladdin, urea was purchased from Tianjin Zhiyuan Co., Ltd, urea and ethanol were of analytical grade and used without further purification.

Synthesis of Anatase. Firstly, appropriate amount of urea, 2\% Span 20 and 5\% PEG600 were added into the dilute aqueous solution of titanium oxysulfate sulfuric acid complex hydrate which was filtered by adding some activated carbon. Then, the mixture solution was transferred into three-necked flask and placed in microwave field at different temperature for $20 \mathrm{~min}$, the resulting solution was washed for several times with $60^{\circ} \mathrm{C}$ deionized water to remove $\mathrm{Fe}^{2+}$ and then washed with absolute ethanol, the white precipitate was dried in a vacuum at $80^{\circ} \mathrm{C}$ for $2 \mathrm{~h}$ and calcined in muffle at $600^{\circ} \mathrm{C}$ for $2 \mathrm{~h}$. Finally, the obtained powders were kept in dryer for further investigation.

\section{Results and Discussion}

Effect of TiOSO $4 \cdot \mathbf{x H}_{2} \mathrm{SO}_{4} \cdot \mathbf{x H}_{2} \mathrm{O}$ Concentration. To determine the impact of $\mathrm{TiOSO}_{4} \cdot \mathrm{xH}_{2} \mathrm{SO}_{4} \cdot \mathrm{xH}_{2} \mathrm{O}$ concentration on crystallinity, 4.08g urea, 2\% Span20 and 5\% PEG600 were put into the diluted $\mathrm{TiOSO}_{4} \cdot \mathrm{xH}_{2} \mathrm{SO}_{4} \cdot \mathrm{xH}_{2} \mathrm{O}(5.4383 \mathrm{~g}, 2.7192 \mathrm{~g}$ and $0.9597 \mathrm{~g})$ aqueous solution with $20 \mathrm{~mL}$ deionized water. The subsequent operations were in line with previous described. Fig. 1a shows XRD patterns of synthesized $\mathrm{TiO}_{2}$ with different $\mathrm{TiOSO}_{4} \cdot \mathrm{xH}_{2} \mathrm{SO}_{4} \cdot \mathrm{xH}_{2} \mathrm{O}$ concentration. Before calcination, the sample exhibited a weak peak corresponding to the (001) diffraction plane of anatase and the calcined samples all showed no peak shift and other new crystalline phase, clearly existed six characteristic peaks indexed to (001), (004), (200), (105), (211), (204) diffraction planes which are matched well with JCPDS file No. 21-1272, indicating that calcined samples were phase-pure anatase and the intensity of diffraction peaks increased by varying $\mathrm{TiOSO}_{4} \cdot \mathrm{xH}_{2} \mathrm{SO}_{4} \cdot \mathrm{xH}_{2} \mathrm{O}$ quality from $0.9597 \mathrm{~g}$ to $5.4383 \mathrm{~g}$, the peaks after $60^{\circ}$ were not obvious with low precursor concentration. With the dilute concentration of reactants, the hydrolysis rate of urea increased and lead to the little and big grain product. Therefore, the concentration of $\mathrm{TiOSO}_{4} \cdot \mathrm{xH}_{2} \mathrm{SO}_{4} \cdot \mathrm{xH}_{2} \mathrm{O}$ is a crucial factor to this process and 5.4383g $\mathrm{TiOSO}_{4} \cdot \mathrm{xH}_{2} \mathrm{SO}_{4} \cdot \mathrm{xH}_{2} \mathrm{O}$ which FOM reached 9.5 with particle size of $17.58 \mathrm{~nm}$ calculated from (101) plane was chosen for next experiments. For each case, one parameter was changed and analyzed while the other factors were kept constant.
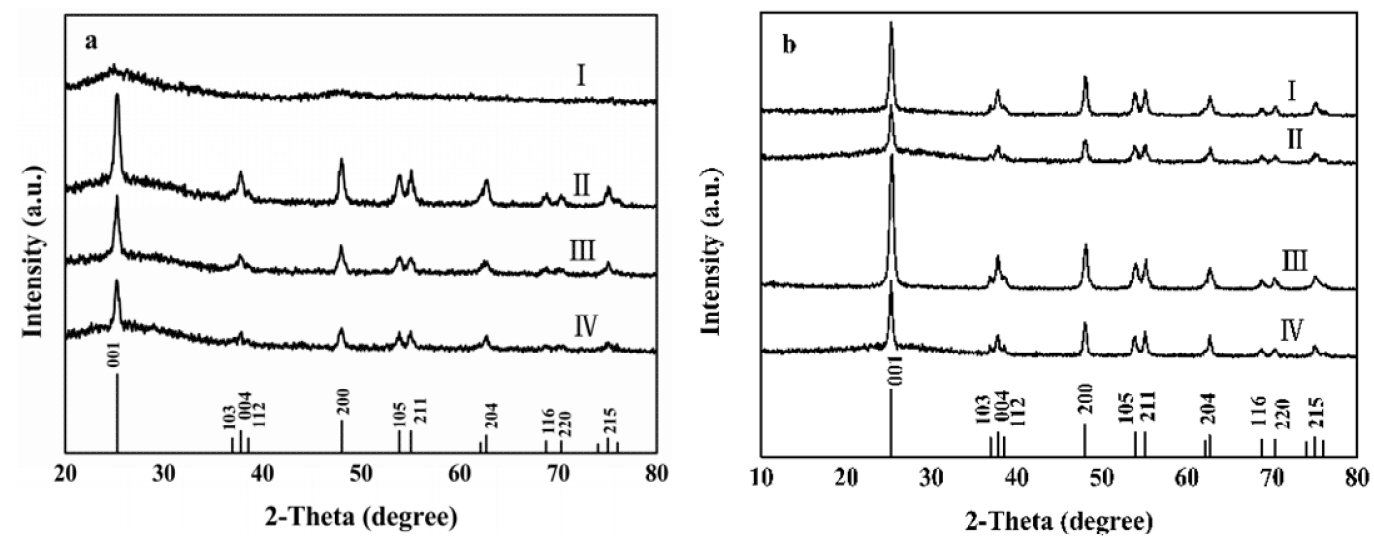

Figure 1. The XRD Patterns of Synthesized $\mathrm{TiO}_{2}$ : (a) with different dosages of $\mathrm{TiOSO}_{4} \cdot \mathrm{xH}_{2} \mathrm{SO}_{4} \cdot \mathrm{xH}_{2} \mathrm{O}$ : I5.4383g before calcinations; II5.4383g calainated at $600^{\circ} \mathrm{C}$; III $2.7192 \mathrm{~g}$; IV0.9597g. (b) with different temperature:I85 ${ }^{\circ} \mathrm{C}$; II $90^{\circ} \mathrm{C}$; III $95^{\circ} \mathrm{C} ; \mathrm{IV} 100^{\circ} \mathrm{C}$

Effect of Urea Dosage. In order to study the effect of urea concentration on particle size and dispersion property. $\mathrm{TiOSO}_{4} \cdot \mathrm{xH}_{2} \mathrm{SO}_{4} \cdot \mathrm{xH}_{2} \mathrm{O}$ was fixed at $5.4383 \mathrm{~g}$ whereas the urea quality varied from $4.08 \mathrm{~g}$ to $20.4 \mathrm{~g}$, the other conditions are the same as mentioned above. SEM images of titania 
obtained from homogeneous precipitation assisted by microwave irradiation are shown in Fig. 2. It can be found that spherical agglomerates were obtained with appropriate urea/ $\mathrm{TiOSO}_{4} \cdot \mathrm{xH}_{2} \mathrm{SO}_{4} \cdot \mathrm{xH}_{2} \mathrm{O}$ ratio, when urea quality increased to $12.24 \mathrm{~g}$, the roughly spherical particles with a diameter of about $1 \mu \mathrm{m}$ were observed while the dispersion property of agglomerates became worse with a further increase of urea/ $\mathrm{TiOSO}_{4} \cdot \mathrm{xH}_{2} \mathrm{SO}_{4} \cdot \mathrm{xH}_{2} \mathrm{O}$ ratio. The concentration of $\mathrm{OH}^{-}$increased in aqueous with larger urea/TiOSO $4 \cdot \mathrm{xH}_{2} \mathrm{SO}_{4} \cdot \mathrm{xH}_{2} \mathrm{O}$ ratio, and caused the greater degree of supersaturation which is beneficial to the formation of small particles. Therefore, $12.24 \mathrm{~g}$ urea was used for further investigation.
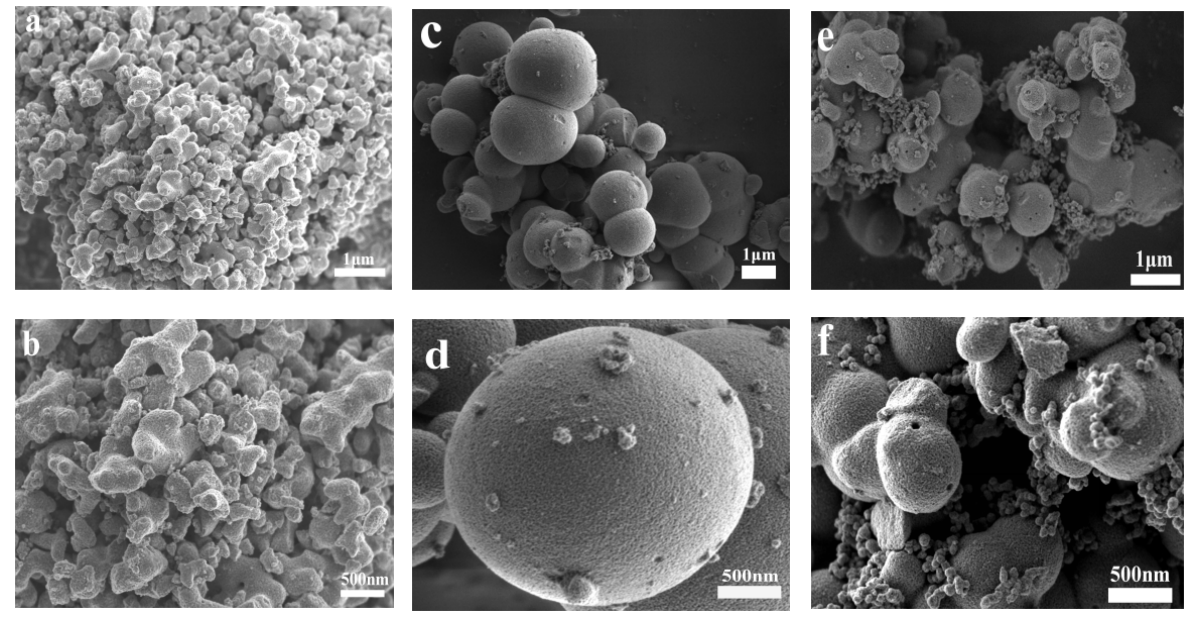

Figure 2. SEM images of representative $\mathrm{TiO}_{2}$ samples synthesized with different urea qualities: (a) $4.08 \mathrm{~g}$; (b) the enlarged SEM image with $4.08 \mathrm{~g}$ urea (c) $12.24 \mathrm{~g}$; (d) the enlarged SEM image with $12.24 \mathrm{~g}$ urea; (e) $20.4 \mathrm{~g}$; (f) the enlarged SEM image with $20.4 \mathrm{~g}$ urea

Effect of Temperature. In this part, 12.24g urea, 2\% Span20 and 5\% PEG600 were put into $5.4383 \mathrm{~g} \mathrm{TiOSO}_{4} \cdot \mathrm{xH}_{2} \mathrm{SO}_{4} \cdot \mathrm{xH}_{2} \mathrm{O}$ in $20 \mathrm{~mL}$ deionized water, the resulting solution was placed in a microwave field at different temperature $\left(85^{\circ} \mathrm{C}, 90^{\circ} \mathrm{C}, 95^{\circ} \mathrm{C}, 100^{\circ} \mathrm{C}\right)$ for $20 \mathrm{~min}$. XRD results in Fig. $1 \mathrm{~b}$ showed that prepared $\mathrm{TiO}_{2}$ were pure-phase anatase, the crystallite size calculated from (101) diffraction peak were $19.78 \mathrm{~nm}, 21.24 \mathrm{~nm}, 17.13 \mathrm{~nm}$ and $23.82 \mathrm{~nm}$ at $85^{\circ} \mathrm{C}, 90^{\circ} \mathrm{C}, 95^{\circ} \mathrm{C}$ and $100^{\circ} \mathrm{C}$, respectively. Although the diffraction peaks at $95^{\circ} \mathrm{C}$ was sharpest, its agglomeration is serious and can not see the spheres from SEM images in Fig. 3c. Temperature is an important factor for nucleus formation and crystal growth, with an increase of temperature, the rate of nucleus formation increased but the super-saturation declined and the kinetic energy of molecules increased which is not beneficial for stabilization and leads to a decrease of nucleation rate. The reaction between $\mathrm{TiOSO}_{4} \cdot \mathrm{xH}_{2} \mathrm{SO}_{4} \cdot \mathrm{xH}_{2} \mathrm{O}$ and urea started at about $80^{\circ} \mathrm{C}$ whereas the isomerization of urea will happen with high temperature. Therefore, an appropriate temperature is vital to this process. Consequently, $90^{\circ} \mathrm{C}$ was chosen as an appropriate temperature through comprehensive consideration to synthesize $\mathrm{TiO}_{2}$. Besides, there are many literatures investigated the type of surfactant used in this reaction [5]. In the process of forming metatitanic acid, the particle surface was positively charged due to the dissociation of hydroxyl, and was easy to attract the anionic, exclude cationic from the solution. Therefore, the anionic surfactants are easier to parcel the particle surface and have very good dispersion effect theoretically, 1.5\% DBS was regarded as comparison object in this experiment, the SEM image was shown in 3d, the more irregular micro-sphere was observed compared with $3 \mathrm{~b}$, and the dispersion property was not improved. So, $2 \%$ Span20 and 5\% PEG600 were employed as surfactants in this study. 

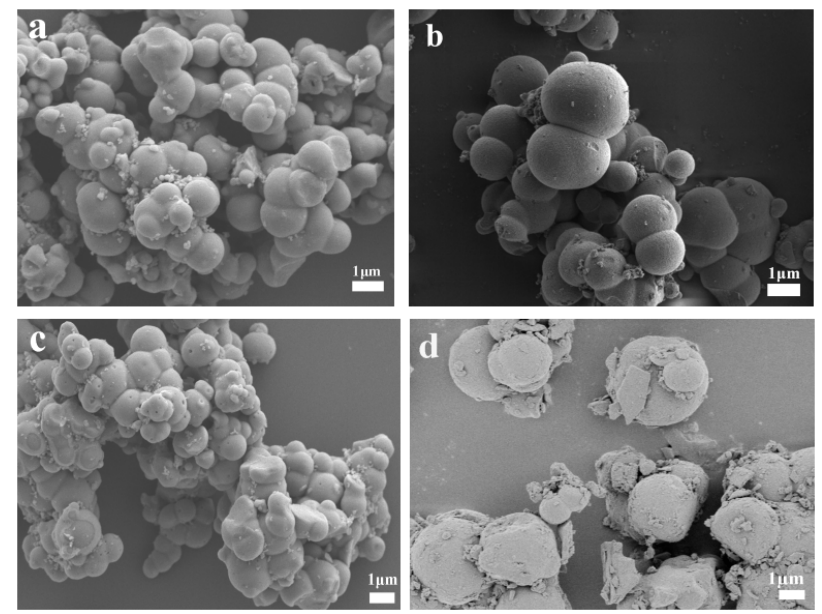

Figure 3. SEM images of different temperatures: (a) $85^{\circ} \mathrm{C}$; (b) $90^{\circ} \mathrm{C}$; (c) $95^{\circ} \mathrm{C}$ and (d) of $1.5 \%$ DBS as surfactant under $90^{\circ} \mathrm{C}$

\section{Conclusion}

Nanostructured $\mathrm{TiO}_{2}$ micro-spheres were synthesized with homegeneous precipitation method assisted by microwave irradiation. The raw materials concentration, temperature and the type of surfactant are crucial to the process of preparing nanostructured $\mathrm{TiO}_{2}$ micro-spheres. The particles with uniform granularity and good dispersion are obtained when the $\mathrm{TiOSO}_{4} \cdot \mathrm{xH}_{2} \mathrm{SO}_{4} \cdot \mathrm{xH}_{2} \mathrm{O}$ quality is 5.4383g, and $12.24 \mathrm{~g}$ urea, 2\% Span20 and 5\% PEG600 in 20ml deionized water are placed in microwave field at $90^{\circ} \mathrm{C}$ for $20 \mathrm{~min}$.

\section{Acknowledgments}

This work was financially supported by Guangdong Department of Water Resources Science and Technology Innovation Project (No. 2015-20).

\section{References}

[1] Landmann M, Rauls E, Schmidt WG, The electronic structure and optical response of rutile, anatase and brookite TiO2, J Phys Condens Mat. 24 (2012) 1614-21.

[2] Vera ML, Leyva G, Litter MI, Simple $\mathrm{TiO}_{2}$ Coatings by Sol-Gel Techniques Combined with Commercial $\mathrm{TiO}_{2}$ Particles for Use in Heterogeneous Photocatalysis, J Nanosci Nanotechno. 17 (2017) 4946-54.

[3] Baneshi J, Haghighi M, Jodeiri $\mathrm{N}$, et al, Homogeneous precipitation synthesis of $\mathrm{CuO}-\mathrm{ZrO}_{2}$ $-\mathrm{CeO}_{2}-\mathrm{Al}_{2} \mathrm{O}_{3}$ nanocatalyst used in hydrogen production via methanol steam reforming for fuel cell applications, Energ Convers Manage. 87 (2014) 928-37.

[4] Gedye R, Smith F, Westaway K, et al, The use of microwave ovens for rapid organic synthesis, Tetrahedron Lett. 27 (1986) 279-82.

[5] Zhu H, Shang Y, Jing Y, et al, El-Toni AM, Zhang F, et al, Synthesis of Monodisperse Mesoporous $\mathrm{TiO}_{2}$ Nanospheres from a Simple Double-Surfactant Assembly-Directed Method for Lithium Storage, Acs Appl Mater Inter. 38 (2016) 25586. 